\section{$\underset{\substack{\text { hommes } \\ \text { \& migrations }}}{ }$}

\section{Hommes \& migrations}

Revue française de référence sur les dynamiques

migratoires

$1320 \mid 2018$

Au prisme de la consommation

\title{
Victor Schœlcher, Journal de voyage en Égypte (1844)
}

Paris, Mercure de France, 2017, 442 p., 8,90€.

\section{Mustapha Harzoune}

\section{(2) OpenEdition}

12 Journals

\section{Édition électronique}

URL : http://journals.openedition.org/hommesmigrations/4098

DOI : 10.4000/hommesmigrations.4098

ISSN : 2262-3353

\section{Éditeur}

Musée national de l'histoire de l'immigration

\section{Édition imprimée}

Date de publication : 1 janvier 2018

Pagination : 169-170

ISBN : 978-2-919040-40-7

ISSN : 1142-852X

\section{Référence électronique}

Mustapha Harzoune, « Victor Schœlcher, Journal de voyage en Égypte (1844) », Hommes \& migrations [En ligne], 1320 | 2018, mis en ligne le 01 janvier 2018, consulté le 06 janvier 2021. URL : http:// journals.openedition.org/hommesmigrations/4098; DOI : https://doi.org/10.4000/ hommesmigrations.4098 
poète Mourad Djebel. La mort de Tahir réveille les peurs de Marceline. "ça a recommencé. Elfe est de nouveau dans H'Histoire." Vivre libre n'est pas aisé à theure où « certains revvaient de vous aus= eulter tes gênes" pour soupeser votre toyauté ou vous museter, en vous coffrant dans une fausse appartenance. Au pays de Descartes, plus te droit de penser! Marceline, Iris ou Fatma ; Bianca, François ou Tahir... quette importance. II s'agit de vivre libre. D'ouvrir ta cage. De desserrer ces noeuds de la société et de l'histoire

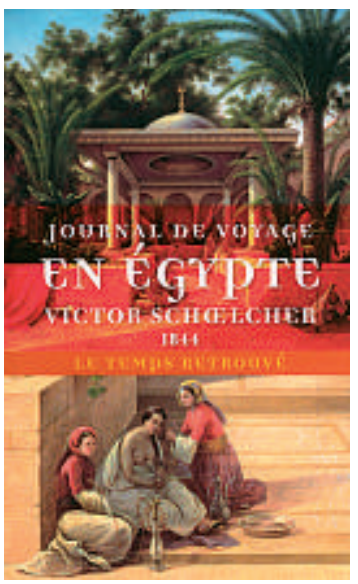

Victor Schœlcher Journal de voyage en Égypte (1844)

Paris, Mercure de France, 2017, 442 p., 8,90€.

Dans le cadre d'un voyage d'étude sur l'esclavage qui le mena de 1840 à $1847 \mathrm{du}$ Mexique au Sénégal en passant par les Antilles, Victor Schœlcher séjourna en Égypte en 1844. Il en rapporta de nombreuses et précises informations sur l'esclavage bien sûr, sur l'antériorité et la prégnance de la civilisation éthiopienne mais aussi sur la vie politique, culturelle, sur l'islam comme sur le sort des plus humbles. qui étranglent, laissent sans voix, invisible. Le coeur lent. Expressive, émou= vante (lire les épisodes de l'abandon, de l'enterrement ou la magnifique lettre de Marceline à Bianca), la phrase, sobre; senourrit de blanesetde signes.Comme tes coeurs tents. Rien de désespéré - " illy a encore tant à découvrir. lly a des personnes chères, en vie" - dans ce bijou d'horlogerie dont les tic-tac et les silences rythment les existences. Et leur devenir. II faut juste (ré)apprendre à placerta lumière:

M. H.

Ce qui peut surprendre le lecteur contemporain, c'est l'exigence intellectuelle, le souci pédagogique, la hauteur de vue de l'auteur qui s'appuie sur une solide documentation, nourrie de rencontres et d'observations de terrain. L'acuité du regard de Schœlcher, le souci des questions sociales restent une source d'inspiration. Lire ce journal, c'est encore aujourd'hui - surtout aujourd'hui-se détourner des diabolisations et globalisations à tout va, remettre du discernement et de la profondeur historique, rappeler qu'il existe des divergences d'intérêts socio-économiques (la fameuse lutte de classes) et qu'une bonne politique extérieure exige, si ce n'est de voir loin, à tout le moins de respecter ses valeurs en ne se trompant pas de partenaire. 


\section{LIVRES}

Les analyses ensuite. Prenons, en ce qu'ils restent d'actualité, la question de l'islam et l'attitude de l'Occident à l'égard des régimes dits arabes. Sur l'islam et le Coran, pas moins de deux chapitres, soit quelque 80 pages d'analyses fouillées et jamais univoques. Peu sensible aux chants des muezzins, plus admiratif des architectures arabes "inégalées", notamment des mosquées, Victor Schœlcher est capable de constater que les cinq prières quotidiennes peuvent constituer la base gymnique de la souplesse des corps et qu'elles offrent quelques vertus hygiéniques. Le lecteur de ce $X X I^{e}$ siècle sera sans doute décontenancé de lire que la charité est la base fondamentale d'un Coran tout rempli du sentiment de bonté et que Mahomet est un homme "moral » et "vertueux ». Pour autant, cela n'empêche nullement l'auteur de pointer quelques tares, à commencer par l'éducation : la "scolastique vide et sans portée " d'un apprentissage reposant sur la récitation mais aussi - perspicacité qui rejoint là des analyses contemporaines (voir Fouad Laroui, Le Drame linguistique marocain Zellige, 2011 dans $H \& M$, $n^{\circ} 1300$ ) - la situation de diglossie entre l'arabe parlé et l'arabe classique. Il pointe la responsabilité des ulémas qui feraient (déjà ?) le peuple "fanatique religieux et ignorant " et raille ce " soin haineux et bizarre" avec lequel "les musulmans cachent leurfemmes ". Si en ces temps lointains les musulmans à la différence des catholiques laissaient aux autres cultes une liberté d'exercice, les choses, depuis, ont bien changé. Comme les opinions donc.

"La brèche est faite " écrit Victor Schœlcher pour signifier qu'un rayon de lumière venue de l'Occident « commence à poindre dans l'islamisme ». Le doute gagnerait jusqu'aux croyants. "Nous souhaitons qu'elle s'agrandisse, car le rapprochement nécessaire entre l'Orient et l'Occident en deviendra d'autant plus facile. Ily a assez longtemps que les haines inséparables de la diversité des religions déchirent le monde; l'heure n'est-elle pas venue de jeter les bases de la seule bonne religion: celle de la fraternité universelle. " Encore faut-il quelques cohérences et, de ce point de vue, Schœlcher critique largement Mohammed Ali considéré comme le fondateur de l'Égypte moderne et le soutien que l'Occident apporte au monarque et à sa politique qualifiée de "barbaries". "Pourquoifaut-il, hélas! Que les grandes lois de la philanthropie préoccupent si peu les hommes qui régissent l'Occident! " M. H. 